\title{
Application of Rehearsal in Orchestra Ensemble Teaching in Colleges and Universities in Conservatory of Qingdao University
}

\author{
Wen $\mathrm{Li}^{1{ }^{1 *}}$, Li Jia ${ }^{2}$ \\ School of Music, Qingdao University, Qingdao, Shandong, China \\ ${ }^{2}$ College of Music, Shanxi Normal University, Taiyuan, Shanxi, China \\ *Corresponding author
}

Keywords: Mozart; Requiem, Comprehensive colleges and universities, an orchestral ensemble lesson, Qingdao University

Abstract: According to the reform measures of classroom teaching, in order to adapt to the requirements of vigorously promoting the reform of classroom teaching methods, according to the new curriculum concept and the law of education and teaching, the "Opinions on Promoting the Reform of Classroom Teaching Methods under the Background of New Curriculum" is formulated and implemented in the classroom. During the period of study in school, Teachers 'teaching should not only rely on books for written and stereotyped teaching, but also give students the opportunity and time to experience and experience the knowledge they have learned, and to carry out practical and autonomous exploration. Therefore, the orchestral ensemble course, which pays more attention to students 'self-experience, has become an indispensable course in many conservatories of music in Colleges and universities. By organizing students to collaborate on the music, this study enables students to gradually try the structure of the symphony orchestra and the way of cooperation among the members of the orchestra in the process of ensemble, and at the same time apply their professional knowledge to practical operation. In the process of completing the materialization and concretization of teaching content, at the same time, it provides professional help and experience for students to choose their careers after graduation. However, due to the different enrollment indicators of art colleges and comprehensive colleges, the emphasis of the corresponding courses is also different. Taking Qingdao University as an example, this paper analyzes the design and application of rehearsal in orchestral ensemble teaching in comprehensive universities. This paper takes Mozart's Requiem as the rehearsal repertoire, first of all, it summarizes the background and characteristics of Mozart's Requiem, secondly, it summarizes the differences between the focus and process of orchestral ensemble teaching in music colleges and comprehensive universities, and studies and discusses the application content and specific situation of orchestral ensemble teaching in Colleges and universities. Finally, it introduces the innovative teaching of adding chorus parts to the orchestral ensemble teaching in Qingdao University to improve the interest and professionalism of the classroom. 


\section{Introduction}

In order to vigorously promote the reform of classroom teaching methods, according to the new curriculum concept and the law of education and teaching, the "Opinions on Promoting the Reform of Classroom Teaching Methods under the Background of New Curriculum" is formulated and implemented in the classroom. During the period of students 'study in school, teachers' teaching should not only rely on books to carry out text and stereotyped teaching. More importantly, students should have the opportunity and time to feel and experience the knowledge they have learned, and carry out practical and autonomous teaching. The development of orchestral ensemble lessons in colleges and universities is also a more natural and reliable way to help students learn and think by themselves.

This paper explores the application of Mozart's "Requiem" in the orchestral ensemble class of Qingdao University, from the background of the creation of "Requiem", song appreciation, many times over the years by the performance version of data access and summary, and compares the emphasis and course process of orchestral ensemble class between music colleges and comprehensive universities. Finally, some suggestions are put forward for the experience and problems in the process of orchestral ensemble teaching in comprehensive colleges and universities.

I hope that through the collection, integration and analysis of books and literature in this paper, more people can understand the importance of orchestral ensemble course for college students and the results of different teaching methods for students at different stages, and understand the teaching mode more suitable for comprehensive college students.

\section{Mozart's Requiem}

\subsection{About Mozart}

Mozart, whose full name is Wolfgang Amadeus Mozart, was born in Salzburg, Austria.Viennese Classical SchoolOne of the representatives, the representative of the classical period, the Austrian composer.

In his short life of 35 years, Mozart completed more than 600 music works of different genres and forms, including operas, symphonies, concertos, sonatas, quartets and other ensemble and ensemble works, as well as a large number of instrumental pieces and solos, covering almost all the music genres at that time. His music reflects the style of the classical period.He perfected a variety of musical genres and, together with Haydn, established the Viennese Classical School.

\subsection{Music structure of Requiem}

\subsubsection{Characteristics of tonality, rhythm and speed}

"Requiem" in D minor as the main key, the use of close relationship modulation. There are some tonal changes in the middle of the work, but it still revolves around the main tone. The beat is dominated by $4 / 4$ time, and only a few phrases adopt other beats. For example, "Beg Your Memories" and "Day of Tears of Pain" use a 12/8 beat, and "Osanna" uses a 3/4 beat[1]。 When composing the Requiem, Mozart had a clear requirement for the playing speed of the music, and basically marked the expected speed, only a few of the music in the Successive Narration did not mark the playing speed.

\subsubsection{Features of the adlapter}

Mozart's "Requiem" band is not very large; the orchestration is only bassoon, bassoon, trumpet, 
trombone, timpani, strings, organ. The instrumental sounds of bassoons, bassoons and trombones are closer to the human voice. Mozart enriched the melody of the human voice through these instrumental sounds, expressing a sad and solemn atmosphere. Timpani and trombone can express solemn music. String music enriches harmony and strengthens the melody of human voice with different rhythms, which fully expresses Mozart's thinking about death. And the inner struggle. In the whole music work, the orchestra plays multiple roles, sometimes repeating the melody of the human voice, sometimes acting as the background of the music, and sometimes echoing with the chorus, playing a role of adjustment and balance.

\subsection{Music Experience of "Requiem"}

Mozart's Requiem is the most frequently played and influential piece in the modern music system and its status is also the most important. This work is Mozart's multi-dimensional comprehensive display of life, ideal, reality, death and so on. And in the form of music, through the combination of instrumental performance and chorus singing, a classical religious mass is deduced.

"Requiem" this work no matter in the arrangement of the work and the cooperation of vocal music, is a typical Mozart style, the work is rigorous and serious, through the use of instruments closer to life: trombone, trumpet, strings, etc. To enrich the melody of the human voice, so as to make the whole music work sad, sad and sad atmosphere. The rich harmonic structure of each part of the string not only enriches and strengthens the melody of the vocal part, but also enables Mozart to express his psychological journey in the process of exploring life, death and ideals.

\section{Enrollment of Art Universities and Comprehensive Universities}

The design of different course content and emphasis is different from the enrollment index of art colleges and comprehensive colleges, and the corresponding emphasis in the course is also different. At the same time, it carries out relatively professional and corresponding education for different types of students. In the class training of orchestral ensemble class, it is essential to grasp the learning ability and stage of the students as a whole in a timely and clear manner. After understanding the students in this respect, we should design a directional curriculum for the overall teaching situation and make targeted training, so as to strengthen the students collectively and help their professional development. While fulfilling the course targets, Attention should also be paid to the improvement and consolidation of students 'personal abilities, so that students can develop professional habits in the process of learning, and provide multi-directional choices for future graduate employment.

\subsection{Art colleges and universities}

In this paper, Shandong University of the Arts as a control object, through the comparison of art colleges and universities and comprehensive colleges and universities of the two different and the same, to find out the variables in the teaching of art colleges and comprehensive colleges (enrollment, classroom focus, student situation), so as to put forward suggestions and guidance for the teaching of comprehensive colleges and universities. 


\subsubsection{Types of enrollment in art colleges and universities}

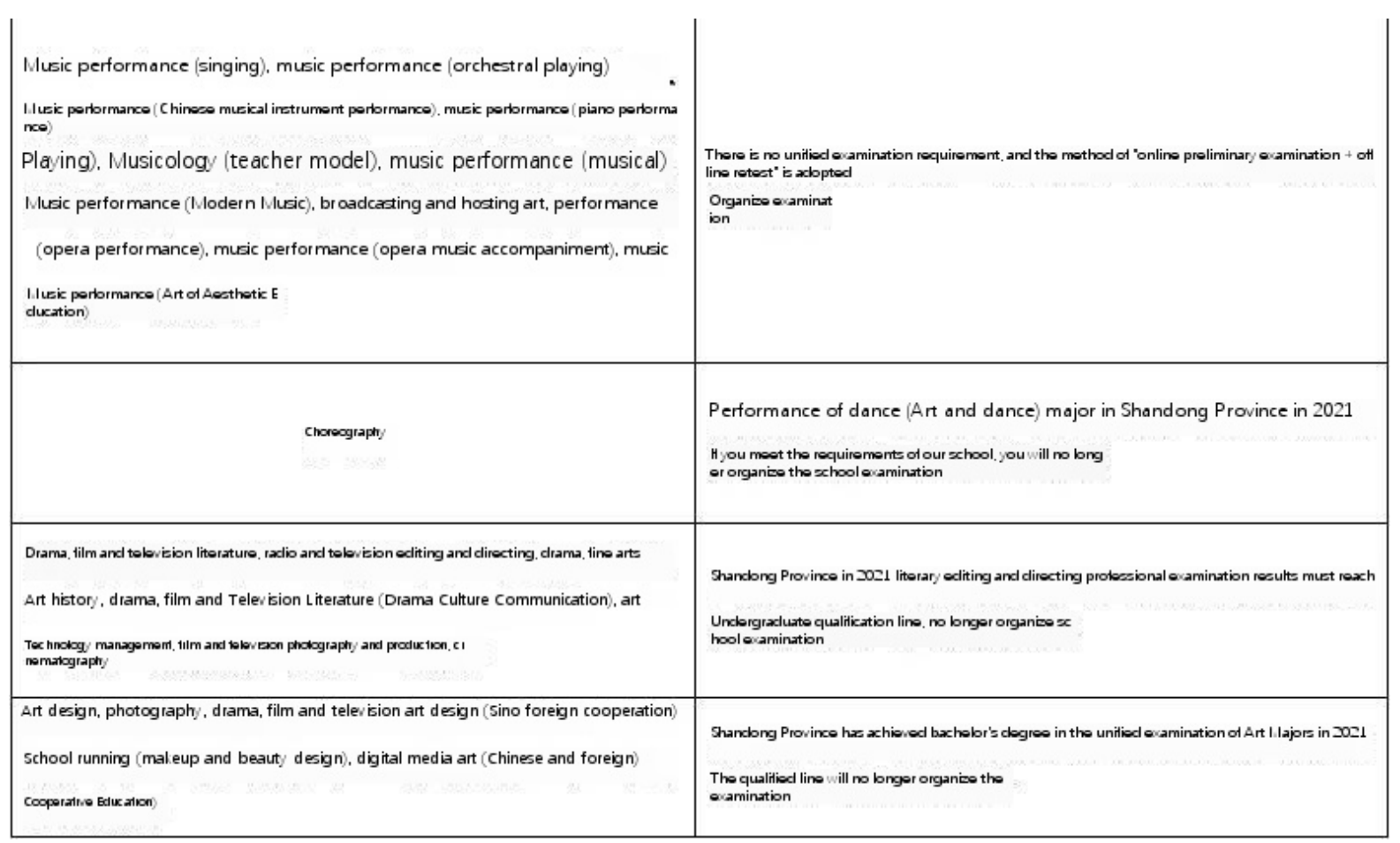

\subsubsection{Admission principles of art colleges and universities}

Chapter V Admission Principles Article 19 The results of admission shall be published to the public by the Shandong Provincial Education Enrollment Examination Institute through the media in accordance with the relevant documents of the Ministry of Education and the Shandong Provincial Education Enrollment Examination Institute. Our college belongs to one of the colleges and universities that independently delimit the score line of cultural courses, which will be based on the cultural achievements of candidates. Self-delimiting the admission control score line of the college's undergraduate and specialist cultural examinations; And according to the professional examination results, combined with the comprehensive assessment of morality, intelligence, physique and beauty, select the best admission; Those who are not admitted will not be notified.

\subsection{Comprehensive colleges and universities}

This paper takes Qingdao University as the contrast object, through comparing the differences and similarities between art universities and comprehensive universities, finds out the variables (enrollment, classroom focus, student situation) in the teaching of art universities and comprehensive universities, so as to put forward suggestions and guidance for the teaching of comprehensive universities.

\subsubsection{Types of enrollment in comprehensive colleges and universities}

\begin{tabular}{|c|c|c|c|c|c|c|c|}
\hline 2021 & Shandong & $\begin{array}{c}\text { Music performance } \\
\text { (keyboard direction) }\end{array}$ & $\begin{array}{c}\text { Art } \\
\text { Category }\end{array}$ & $\begin{array}{c}\text { Arts (regardless of } \\
\text { arts and sciences) }\end{array}$ & $\begin{array}{c}\text { Advance approval of } \\
\text { art undergraduate }\end{array}$ & $\begin{array}{c}\text { Do not mention } \\
\text { subject requirements }\end{array}$ \\
\hline 2021 & Shandong & $\begin{array}{c}\text { Music performance } \\
\text { (national orchestral } \\
\text { direction) }\end{array}$ & $\begin{array}{c}\text { Art } \\
\text { Category }\end{array}$ & $\begin{array}{c}\text { Arts (regardless of } \\
\text { arts and sciences) }\end{array}$ & $\begin{array}{c}\text { Advance approval of } \\
\text { art undergraduate }\end{array}$ & $\begin{array}{c}\text { Do not mention } \\
\text { subject requirements }\end{array}$ \\
\hline 2021 & Shandong & $\begin{array}{c}\text { Music Performance (Vocal } \\
\text { Direction) }\end{array}$ & $\begin{array}{c}\text { Art } \\
\text { Category }\end{array}$ & $\begin{array}{c}\text { Arts (regardless of } \\
\text { arts and sciences) }\end{array}$ & $\begin{array}{c}\text { Advance approval of } \\
\text { art undergraduate }\end{array}$ & $\begin{array}{c}\text { Do not mention } \\
\text { subject requirements }\end{array}$ \\
\hline
\end{tabular}




\begin{tabular}{|c|c|c|c|c|c|c|c|}
\hline 2021 & Shandong & $\begin{array}{c}\text { Music performance } \\
\text { (Western orchestral } \\
\text { direction) }\end{array}$ & $\begin{array}{c}\text { Art } \\
\text { Category }\end{array}$ & $\begin{array}{c}\text { Arts (regardless of } \\
\text { arts and sciences) }\end{array}$ & $\begin{array}{c}\text { Advance approval of } \\
\text { art undergraduate }\end{array}$ & $\begin{array}{c}\text { Do not mention } \\
\text { subject requirements }\end{array}$ \\
\hline
\end{tabular}

\subsubsection{Admission principles of comprehensive colleges and universities}

In Shandong Province. Shandong Provincial Education Enrollment Examination Institute is above the provincial art undergraduate cultural admission control score line, according to the college entrance examination cultural scores from high to low and follow the enrollment plan of 1 : 1.5 ratio to file to colleges and universities, school admission according to the school examination or provincial unified examination professional scores from high to low. When there are parallel scores of professional scores, priority should be given to candidates with high cultural scores in the college entrance examination. Among them, candidates who apply for the major of musicology (theoretical direction) must score more than 400 points (including) in the cultural courses of the college entrance examination, and those who fail to do so will not be admitted. Candidates who apply for fine arts majors must score 326 points (including) or more in the provincial professional unified examination, and those who fail to do so will not be admitted.

\section{Enrollment Characteristics of Art Universities and Comprehensive Universities}

\subsection{Characteristics of Art College Students}

From the analysis of the above materials, we know that the enrollment characteristics of art colleges and universities are as follows: cultural courses are self-delimited, and articles are specially arranged. Art colleges and universities pay more attention to students 'professional ability and the requirements for cultural courses are lower than those of comprehensive colleges and universities. Ranking is also the ranking of students 'professional achievements through the score line drawn by colleges and universities.

So, to sum up. Students in art colleges and universities have relatively strong ability in professional courses, and pay more attention to students 'professional ability when recruiting students. While cultural courses reach the score line, they use professional courses to recruit students.

\subsection{Characteristics of students in comprehensive colleges and universities}

From the above material analysis, we know that the enrollment characteristics of comprehensive colleges and universities are as follows: cultural courses are enrolled according to the line arranged by the Bureau of Education. In individual majors, there are self-delimited lines (higher than the line of cultural courses arranged by the Bureau of Education). After crossing the line, they are enrolled according to the ranking of professional achievements. In the case of the same professional course scores, they are admitted according to the level of cultural courses. Students with high scores in cultural courses are preferred. Comprehensive colleges and universities pay more attention to the comprehensive ability of students, after the cultural courses meet the requirements of the Bureau of Education and society, then see whether the students 'professional ability is too hard. The requirements for cultural courses are higher than those of art colleges and universities. Comprehensive schools compare students 'comprehensive scores when recruiting students, and pay more attention to students' comprehensive situation than art colleges and universities.

So, to sum up. The comprehensive ability of students in comprehensive colleges and universities is relatively strong, and they pay more attention to the comprehensive ability of students when recruiting students, which will weaken the performance of professional courses. At the same time 
when the cultural courses reach the score line, the principle of enrollment is based on the scores of professional courses.

\section{Orchestral Ensemble Training}

Orchestra ensemble course is a course that allows students to conduct systematic guidance and orchestra training on the basis of professional conductors. Students who participate in the training of orchestral ensemble courses will receive targeted training in the cooperation of orchestras and instruments, and will be more skilled in instrumental music learning, concerts and cooperation with other instruments.

Therefore, whether for art colleges or comprehensive colleges, orchestral ensemble course is indispensable for students "training, and it is also a "preparatory class" for qualified musicians and performers.

\subsection{Orchestra Ensemble Course in Art Colleges and Universities}

Students in art colleges and universities have relatively good professional courses, and the focus of their training is also on the study of professional musical instruments, so their students will have more time to practice their professional content. Therefore, for the training of orchestral ensemble class, students in art colleges and universities focus more on the overall band cooperation and detailed emotional processing. In terms of intonation and rhythm, students can learn independently after class, and teachers can solve individual students 'problems through simple slow ensemble.

The training of orchestral ensemble course in art colleges and universities pays more attention to the harmony and consistency of the voices of each part in the orchestra, so that each student can complete the fine processing of feelings on the basis of accurate intonation and rhythm, so as to enrich the content of music and reveal more emotions.

To sum up, according to the admission criteria of art colleges and universities, students are generally more professional, and schools pay more attention to the training of students 'professional skills in teaching, so students can complete the rehearsal of orchestral ensemble lessons before class. In class, teachers do not have to spend too much time adjusting the basic content of music such as students 'intonation and rhythm. More class time will be spent on the detailed rehearsal of the music, the sound coordination of the band, and the emotional expression of the music.

\subsection{Orchestra Ensemble Course in Comprehensive Colleges and Universities}

Students in comprehensive colleges and universities have strong professional comprehensiveness, so the school pays more attention to the teaching of students 'professional comprehensiveness in the teaching curriculum plan of students, and there are more professional sub-subjects, so students can not complete the music exercises needed in class in time before class. Therefore, in class, teachers need time to help students complete the music preview and deal with basic problems such as intonation and rhythm. Through the division of instruments and voices to carry out targeted training, to achieve a preliminary understanding of the music. And in the training of orchestral ensemble class in comprehensive colleges and universities, teachers mainly focus on the preliminary understanding of music, music knowledge explanation and interesting performance (adding vocal music and dance training).

The training of orchestral ensemble course in comprehensive colleges and universities pays more attention to the preliminary practice of music and the study of background knowledge of music for each student in the orchestra. After completing this teaching goal, the details of music are further dealt with, and other professional students are arranged together. It not only completes the mastery 
of the repertoire by the students of the orchestra, It also adds other specialties to the music, which increases the degree of restoration of the music.

To sum up, according to the enrollment standards of comprehensive colleges and universities, students generally have strong professional comprehensiveness, and schools pay more attention to the training of students 'professional comprehensiveness in teaching, so students can not complete the rehearsed repertoire in orchestral ensemble class in time before class. In the classroom, teachers need time to adjust the basic content of music such as students 'intonation and rhythm. Part of the class time is spent on the basic processing of the music, and the rest of the time is spent on the details of the music and enriching the emotions. When the repertoire is more mature, add appropriate other majors to improve the framework of the music, so that students can have a complete understanding of the content of the music.

\section{Curriculum Design and Arrangement of Orchestra Ensemble in Comprehensive Colleges and Universities}

In order to make a more detailed and specific demonstration of the curriculum design and arrangement of the orchestral ensemble course in comprehensive colleges and universities, this paper uses Mozart's Requiem as the classroom repertoire to explain its classroom content. Make a summary of the content from the preparation before class to the end of class. I hope that through the collection, integration and analysis of books and literature in this paper, more people can understand the importance of orchestral ensemble course for college students and the results of different teaching methods for students at different stages, and understand the teaching mode more suitable for comprehensive college students.

\subsection{The application of Mozart's Requiem in the orchestral ensemble class of Qingdao University}

\subsubsection{Preparation before class}

Before class, teachers distribute the music score first, so that students can have a basic understanding of the music score in the spare time of class, and print the paper version by themselves, and take it with them in class. The content of the class will be consulted, sorted out and sent to the group for students to read by themselves. Let students have a certain understanding of the background and structure of the music, and have a deep feeling of orchestration and emotion.

Arrange the chief students of each part to organize and lead the rest of the students to rehearse before class, unify the playing methods (bow, fingering, ventilation) of the music, and mark them on the score to facilitate the smooth progress of the class. The chief first practiced the rhythm and intonation of the rest of the students in this part, and they could watch the audio materials together. Have a general understanding of the basic melody trend of the music, and then play to solve the basic problems to ensure the basic synchronization of vocal music.

\subsubsection{In class}

At the beginning of the class, the teacher first checks the group training, tests the people of different parts separately, and observes whether the students can play their own parts independently and cooperate in the part playing. Give individual guidance to the students who have problems, raise problems and urge them to solve them.

After basically solving the problem of rhythm and intonation, the teacher explains the music knowledge of the music (background, style, composer, musical form and harmony) so that students can have a knowledge understanding of the work, enrich their knowledge, broaden their horizons, 
and combine their book knowledge with the actual content of the repertoire.

Teachers organize students to play in the orchestra ensemble, solve the problems of each part after the orchestra ensemble, deal with the details, and pay attention to the interspersed teaching of music knowledge points, so that students can learn music knowledge in the process of playing, the two alternate, and expand the efficiency of classroom time. Teachers concentrate on dealing with the problems in the orchestra ensemble and solve them sentence by sentence. In order to achieve a more harmonious stage.

When students can play the music completely and handle the details properly, join other professional students to complete the music. For example, in Mozart's Requiem, after the orchestra has completed the training of the accompaniment part, the students who join the chorus cooperate in the whole piece. While the orchestra is playing, the vocal music students are singing, which improves the integrity of the music. Students can also feel the charm of the music and help students to understand the environment of the orchestra in advance.

\subsubsection{Practice after class}

After class, the teacher arranges the chief students of each part to consolidate and deal with the problems existing in the class for the rest of the students of the voice part, to train the inaccurate tone and rhythm problems separately, and to increase the frequency of joint practice for the uncoordinated part of the voice part, so as to achieve the goal of smooth ensemble.

\subsection{Innovation of Orchestra Ensemble Class in Qingdao University}

In view of the different basic conditions of students, for the orchestral ensemble class in comprehensive schools, we should focus on helping students deal with music problems and music knowledge, and make bold innovations, adding different voices to supplement the overall structure of the music.

The orchestral ensemble class of Qingdao University has carried out research and practice on classroom innovation. In the rehearsal of Mozart's Requiem, after the students of the orchestra have completed the basic training, when the music is basically formed, the teacher joins the students of the vocal part to complete the work together. Let students not only have an overall understanding of the music trend of the orchestra, At the same time, it also has a general idea of the direction of other voices. While the orchestra is playing, vocal music students sing, which improves the integrity of the music, and students can also feel the charm of the music, and help students to understand and exercise the orchestra environment in advance.

\subsection{Design and Application of Rehearsal in Orchestra Ensemble Teaching in Colleges and Universities}

The rehearsal in the teaching of orchestral ensemble in colleges and universities can be divided into the following aspects: to pave the way for knowledge before class, to arouse students 'interest, and to organize exercises by the chief voice department; In class, teachers consolidate knowledge, find out problems and provide guidance to help the performance organization cooperate. Review and consolidate the music content in time after class, improve familiarity, check and fill gaps.

However, it is worth noting that because music education in comprehensive colleges and universities focuses more on the cultivation of comprehensive music, students 'professional practice time cannot be guaranteed, so the repertoire should be selected as far as possible, which is easy to use and familiar with and interested in, and the repertoire that is too difficult and too remote should be avoided as far as possible, so as not to discourage students' enthusiasm for learning. Choose a 
track that is easy to use. It can cultivate students 'cooperation and obedience in the orchestra in a relatively simple and relaxed atmosphere, enrich the music through the innovation of simple repertoire (adding students of different majors to perform together, etc.), and achieve the purpose of orchestral ensemble class.

\section{Conclusion}

The requirements of the state for the two dimensions of university curriculum content and university curriculum model are constantly changing, and there are more clear requirements for the direction and process of cultivating the comprehensive ability of university students. The reform measures of classroom teaching are to vigorously promote the reform of classroom teaching methods, according to the new curriculum concept and the law of education and teaching. To formulate "Opinions on Promoting the Reform of Classroom Teaching Methods under the Background of the New Curriculum" and implement them in the classroom. Therefore, it is also very important for students to acquire effective knowledge in different schools.

By comparing the enrollment policies and principles of art universities and comprehensive universities, this paper draws out the differences of the students enrolled, and summarizes the training methods of orchestral ensemble course suitable for comprehensive universities, so as to teach students as much knowledge as possible in a limited range. To help students in different schools achieve the purpose of orchestral ensemble lessons through different teaching methods.

I hope that through the collection, integration and analysis of books and literature in this paper, more people can understand the importance of orchestral ensemble course for college students and the results of different teaching methods for students at different stages, and understand the teaching mode more suitable for comprehensive college students.

\section{Acknowledgement}

As I approach the end of this article, I am writing this note with excitement and gratitude.

Thanks to my colleagues and friends for their help.

Finally, due to my limited academic level, this paper has some inadequacies, please teachers and schoolmates to criticize and correct.

\section{References}

[1] Tian Kewen and Chen Yong. History of Western Music. Wuhan University Press, 1999:106-108.

[2] On the Musical Structure and Central Theme of Mozart \& LT requiem \& GT, Tian Kewen, Chen Yong. History of Western Music. Wuhan University Press, 1999:106-108.

[3] Dazhong poster News] These majors will cancel school exams or enrollment! Shandong University of Arts announces 2021 Undergraduate Enrollment Professional examination announcement 2020-12-16

[4] .http://college.gaokao.com/school/tinfo/326/luqu/

[5] http://zhaosheng.qdu.edu.cn/static/front/qdu/basic/html_web/zsjh.html6,http://zs.qdu.edu.cn/info/1006/1380.htm 